\title{
Chapter 4 \\ From Hydropower Construction \\ to National Park Creation: Changing \\ Pathways of the Nu River
}

\author{
Yu Xiaogang, Chen Xiangxue and Carl Middleton
}

\subsection{Introduction}

The Nu River, also known as the Upper Salween, is one of China's sixteen major cross-border rivers. It originates from the Tibetan Plateau, and runs through Yunnan Province of China, before entering Myanmar. Well-known for its rich biodiversity, the $\mathrm{Nu}$ River and surrounding areas are home to more than 4,300 plants species, of which 24 species fall under the first and second national protection classes ( $\mathrm{Nu}$ Prefecture Forestry Bureau 2015). In acknowledgement of this, the Nu River is one of the "Three Parallel Rivers" (along with the Lancang and Jinsha Rivers), which is the largest World Heritage site in China. Furthermore, many ethnic groups live within the basin, including Lisu, Nu, Dulong, Bai, Pumi, Yi, Tibetan, Naxi and Jingpo.

There has been considerable debate in China over the past two decades about the fate of the $\mathrm{Nu}$ River. In contrast to most major rivers in China, the mainstream of the $\mathrm{Nu}$ River is largely free flowing, with the exception of two hydropower dams near the headwater. Yet, over the past two decades, many of its tributaries have been dammed for hydropower and irrigation (Ptak 2014). This chapter explores the range of visions for the Nu River and the extent to which they have materialized through exploring five 'pathways', namely (see also Yu et al. 2018):

- The hydropower construction pathway that details how China's government developed a strategy for promoting hydropower dam construction in the 1990s as a means of accelerating national economic growth. It incorporates projects across two scales, namely (a) large dams under the West-East Power Transfer (WEPT) regional development scheme that led to plans for a 13-dam cascade on

Yu Xiaogang, Director, Green Watershed; Email: greenwatershed@163.com.

Chen Xiangxue, Project Officer, Green Watershed; Email: chenxx417@163.com.

Dr. Carl Middleton, Director, Center of Excellence for Resource Politics in Social Development, Center for Social Development Studies, Faculty of Political Science, Chulalongkorn University; Email: carl.chulalongkorn@gmail.com.

(C) The Author(s) 2019

C. Middleton and V. Lamb (eds.), Knowing the Salween River: Resource Politics

of a Contested Transboundary River, The Anthropocene: Politik-Economics-

Society—Science 27, https://doi.org/10.1007/978-3-319-77440-4_4 
the Nu River mainstream; and (b) medium- and small-scale dams for provincial or prefecture-level initiatives.

- The civil society river protection pathway that explores the significance of changing society-state-nature relations in China. This pathway is intertwined with the other pathways, including resistance to the hydropower construction pathway, and in support of environmental protection via national parks and energy reform. It emphasizes how democratic space has - to an extent - been produced and utilized to engage high-level government policy objectives on "Ecological Civilization."

- The energy reform pathway that details the implications of China's current electricity surplus and shifting policy positions on climate change and renewable energy, in particular for the hydropower dam pathway.

- The national park pathway that documents how the local government is now pursuing the establishment of national parks, which will give priority to ecological protection. This pathway to a certain extent also reflects the transformation of development thinking over the recent decade in China.

- The water conservancy pathway that seeks to reframe earlier large hydropower dam plans as multi-use projects for irrigation and flood/drought management. This plan has only recently emerged, and few details are in the public domain.

\subsection{Methodology}

The method adopted in this chapter is that of development pathway research. Within this approach, development pathways are defined as "... the particular directions in which interacting social, technological and environmental systems co-evolve over time" (Leach et al. 2010: xiv). The study of a development pathway entails analyzing how different actors' visions for the basin are being formulated and acted upon, including the narratives produced, and the decision-making processes invoked. Overall, the analysis of pathways is a useful heuristic tool to render visible options that exist - or that are proposed - and hence to evaluate their implications for a range of policy goals for the future.

We reviewed relevant policies, legal frameworks and operational guidelines relating to the $\mathrm{Nu}$ River Basin's development and environmental protection at the national and local levels (see also $\mathrm{Yu}$ et al. 2018 for further details). We also conducted institutional and actor analysis, drawing on an extensive literature review, as well as in-depth interviews with government officers, experts and environmental NGO staff (Table 4.1: In-depth interviews conducted). Interviews were also conducted in two communities in Nu Prefecture and the Baoshan Area. Drawing on their role as leaders in the $\mathrm{Nu}$ River protection campaign, Green Watershed also contributed their firsthand experience to inform this research. 
Table 4.1 In-depth interviews conducted

\begin{tabular}{l|l}
\hline Government & - National Energy Agency (NEA) \\
agencies & - National Development and Reform Commission (NDRC) \\
& - Ministry of Environmental Protection (MEP) \\
\hline Experts & - Expert from the Energy Research Institute, NDRC \\
& - Expert from the Department of International Economic Cooperation, \\
& NDRC \\
& - Expert from the China Hydropower Engineering Consulting Group Co. \\
& - Expert from the Research Center of Environment and Development, \\
& Chinese Academy of Social Sciences \\
& - Expert from the China Institute of Water Resources and Hydropower \\
& Research \\
& - Expert from the Center for the Study of Contemporary China \\
\hline NGOs & - Green Earth Volunteers \\
& - Friends of Nature \\
& - International Rivers \\
& - Hengduan Mountain Research Institute \\
\hline
\end{tabular}

Source The authors

\subsection{The Transformation of China's Development Thinking}

Government plans for the $\mathrm{Nu}$ River have been defined by several critical turning points. From the initiation of plans for large hydropower dam construction in the late 1990s to the decision to suspend these plans in February 2004 by Premier Wen Jiabao (2003-2013), the local government has played a key role. Overall, key elements of the local government have maintained a commitment to hydropower construction in collaboration with project developers, and this obstructed the exploration of other options for the basin over the 2000s. However, in November 2012, the central government upgraded its "Ecological Civilization" policy to become a national strategy, and proposed the establishment of a national park system. Shortly afterwards, the Yunnan Provincial government and Nu Prefecture government began to advance new plans accordingly.

More broadly, China has witnessed significant policy reorientation. In 1978, China halted its "class struggle as core" approach, and reoriented towards a measured policy of "opening up" the country to private investment. Over the following three decades, economic growth was a central priority, and socio-economic development of overriding importance, with the goal of meeting the growing material and cultural needs of China's population. However, the pursuit of rapid economic growth led to a long-term pattern of development that could be described as high-input, high-pollution, high-energy-consumption and low-efficiency, and which did not attain a broad-based sustainable mode of development. This not only resulted in a series of social problems, such as an increasing gap between the rich and the poor, capital rent-seeking and political corruption, but also led to environment degradation, including consumption of vast amounts of natural resources, serious pollution and the degradation of ecological systems. 
For several reasons, these challenges urged China's leaders to redirect the country's strategy of economic development towards achieving a more comprehensive form of development of the economy, society and the environment. Firstly, China has a low amount of natural resources per capita, and the growing volume of resource utilization together with low energy efficiency has gradually led to an economic growth bottleneck (partly-addressed by China's growing resource imports). Secondly, with living standards improved for many, there is a growing demand for a better environment. Rising public unrest trigged by environmental pollution has raised questions about government accountability and challenged social stability. Thirdly, China's economic growth has been paralleled by a growing geopolitical role, in which China is playing a more important role in international cooperation and global governance. China is seeking to conform with green low-carbon development trends that are emerging globally, and wishes to promote its competitiveness and influence in the international arena (Ronghua 2012).

The Central Committee of the Communist Party of China (CPC) gradually accepted the concept of sustainability, with the 15th Party Congress held in 1997 adopting a strategy of sustainable development and the 16th Party Congress held in 2002 establishing principles of resource savings and an environment-friendly society. The 17th Party Congress held in 2007 recognized a good ecological environment as one of the important requirements for achieving a well-off society by 2020. However, even as the concept of sustainability has gradually gained acceptance, economic development still remains the first priority. Environmental protection policies are subordinate to (economic) development needs, and thus the old development model has not fundamentally changed.

The 18th Party Congress held in 2012, however, appears to have been a turning point. The report that came out of the meeting included a whole chapter highlighting the construction of an "Ecological Civilization" for the people's wellbeing, and solidified a long-term national development strategy towards attaining it. This meeting adopted the revised Constitution of the CPC, declaring: "The CPC will lead the Chinese people to build a socialist ecological civilization." In the fifth plenary session of the Congress, the General Secretary of the Communist Party of China, Xi Jinping, put forward five new development concepts: innovation, coordination, greening, openness and sharing. Ecological Civilization and the five development concepts formed the development guidelines for China's 13th five-year plan (2016-2020).

\subsection{The Hydropower Development Pathway}

In the late 1990s, Premier Li Peng's (1988-1998) retirement left behind an economic bubble in China's coastal areas and a legacy of underdevelopment in the Western regions. The Asian Financial Crisis of 1997 resulted in the stagnation of 
China's foreign trade and the shrinking of its export-oriented economy, while major flooding in 1998 also harmed the economy. Premier Zhu Rongji (1998-2003) led the new State Council to address these challenges by expanding domestic demand to create an economic "soft landing" (Yonglin 2006). The country's development pattern shifted from an export-oriented economy alone to one that also prioritized investment in undeveloped regions of Western China.

In 2000, the central government launched the Western Region Development Strategy (2000-2020). Within this approach, the "West East Power Transfer" (WEPT) strategy supported large dam construction in Southwest China to transmit electricity to the industrialized Southeastern seaboard where power demand was high and resources to produce electricity limited (Magee 2006; Dore et al. 2007). The WEPT strategy was favored by China's leaders because designing plans for the development of China's western water resources allowed the WEPT strategy to promise to not only meet the electricity demands of Eastern China, but also stimulate economic growth in the West of the country (Peiyan 2010). In this policy discourse, hydropower was considered a clean and renewable energy. Yet, Southwest China, where the projects were to be built, is also the area with China's best-preserved ecology, most abundant biodiversity, and largest ethnic minority population, thus raising the risk of ecological and social harms due to the projects.

\subsubsection{Dissolution of the State Power Corporation}

China's continued economic liberalization under Premier Zhu Rongji led to the reform of state-owned enterprises (SOEs). The power generation section of the monopoly SOE State Power Company was split into five companies (Huaneng, Datang, Huadian, Guodian and China Power Investment Corporation), while the power grid section was split into the State Grid and the Southern Power Grid (Xiaobing 2003). Following this reform, the five power generation companies began competing to increase their profits through bids to build hydropower dams on domestic rivers mainly in Southwest China, which became known as the "river-enclosure movement" (Xiaohui/Baiying 2010). The companies claimed that these hydropower projects were key to China's national energy strategy.

While reform of SOEs was needed to improve their economic performance, under WEPT the central government also unleashed market forces to drive hydropower development. Despite a strong emphasis on planning and environmental impact assessment (EIA), the government could not control the SOEs. Furthermore, the local and national government themselves were often captured by the benefits of strong capital forces, including the generation of revenues from taxes and various fees. Moreover, SOEs often relied on corrupt government officials to obtain project approval. 


\subsubsection{Local Government Response to the WEPT Strategy and $\mathrm{Nu}$ River Hydropower Plans}

There are six rivers flowing through Yunnan Province, with the most profitable for hydropower development being the $\mathrm{Nu}$, Lancang and Jinsha Rivers. Yunnan Province thus became the main focus of WEPT. The Nu River has 36,400 megawatts (MW) of potential hydropower resources and accounts for about one-third of the total hydropower capacity in Yunnan. It was viewed by the government and project developers as one of China's largest potential hydropower resources yet to be developed. The total investment of the proposed thirteen dam cascade proposed for the Nu River was 89.65 billion RMB. When completed, the total annual income from the 13 hydropower dams was anticipated to be more than 30 billion RMB. Meanwhile, annual state revenue would increase by 5.20 billion RMB and annual local revenue for Yunnan Province would increase by 2.72 billion RMB, of which the $\mathrm{Nu}$ Prefecture Government would obtain 1 billion RMB of tax revenue (Yaohua/Jiankun 2004).

In November 2000, the Yunnan Provincial government responded to the strategy of WEPT by affirming its intention to speed up the development of the hydropower industry (Hao 2000). On 31st January 2003, the Yunnan Provincial government signed an "Agreement on promoting the cooperation of power development in Yunnan" with the Huadian Group. Subsequently, on 10th July 2003, the Yunnan Huadian $\mathrm{Nu}$ River Hydropower Company was jointly established by Huadian Group (51\%), Yunnan Energy Investment Group (20\%), China Resources Power Holdings (19\%) and Yunnan Power Investment (10\%).

Yet, in the same month of the creation of the Yunnan Huadian Nu River Hydropower Company, on 3rd July 2003, the UNESCO World Heritage Committee voted to list the "Three Parallel Rivers" as a World Nature Heritage site. This listing offered a different development option for both the $\mathrm{Nu}$ River and the $\mathrm{Nu}$ Prefecture government. However, the local government quickly initiated a propaganda campaign to ensure that hydropower development was the option to be prioritized. For example, the Secretary of the Nu Prefecture government, Xie Yi, requested each government department to collectively write an article explaining that hydropower was "the only way to facilitate Nu River development" (later to be published as "An inevitable choice for the Nu River"). The aim of the articles was to influence civil servants' views on hydropower development. Additionally, the local newspaper and radio began reporting daily on the significance of hydropower to various industries. When Cha Chaoou, a government official of Lisu origin in charge of the prefecture's poverty alleviation program, pointed out that there were many ways to alleviate poverty and that hydropower development was not the only option, he was quickly removed from his position (Bizhong 2004). 


\subsubsection{Challenges from the State Environmental Protection Administration}

The State Environmental Protection Administration (SEPA) played a key role in the debate over the $\mathrm{Nu}$ River's development pathway. With the implementation of China's EIA Law on 1st September 2003, SEPA gained the authority to question EIA reports and processes, and subsequently challenged the EIA of the Nu River hydropower development plan. SEPA's main criticism centered on the fact that the EIA report was based on the "Regulations for River Basin Environmental Impact Assessments" issued in 1992. As there were technical differences between these regulations and the new EIA Law, SEPA questioned the overall credibility of the $\mathrm{Nu}$ River Hydropower Development Planning Unit and the EIA Unit of the Beijing Engineering Corporation (Yikun 2004).

Following a review meeting held by the National Development and Reform Commission on $\mathrm{Nu}$ River hydropower planning in Beijing on 12th-14th August 2003, SEPA held two expert forums on ecological environment protection and hydropower development in the Nu River Basin on September 3rd and October 21st 2003. Following objections raised around the EIA report, the media flagged the issue as a public concern. Yang Chaofei, Director of the Natural Ecological Protection Division of SEPA, began to question the hydropower boom and the ecological impact of dams (Chaofei 2003). In this debate, he also introduced the report of the World Commission on Dams (WCD 2000) into the discussion in China about hydropower. These studies informed the cautious attitude and discourse of SEPA toward large hydropower dams on rivers in China's Southwest.

The $\mathrm{Nu}$ River hydropower planning also stimulated public debate. Chinese environmental NGOs cooperated with the public, media and experts to conduct a series of advocacy campaigns (see below).

\subsubsection{Suspension and Consequence of the Nu River Hydropower Plan}

In February 2004, Premier Wen Jiabao (2003-2013) officially suspended the $\mathrm{Nu}$ River hydropower development plan. However, project proponents continued to support the projects and decision-making on the future of the $\mathrm{Nu}$ River became complicated. Supporters of hydropower construction applied three new strategies: (1) form an alliance with the media to influence public opinion; (2) create a hydropower nationalism discourse; and (3) cultivate pro-hydropower academics.

For hydropower developers, the media had become a challenge to them as it tended to report civil society opinions against the dams. Hydropower developers thus saw it necessary to create hydropower-friendly media to cultivate a discourse endorsing dam development. This strategy manifested itself in the emergence of a group of on-line writers, including Zhang Boting, Fang Zhouzi, and Sima Nam, 
who positioned themselves against the civil society movement seeking to halt large dam development.

Relatedly, a 'hydropower nationalism' discourse emerged that centered on framing river protection as a Western country-induced plot against China. The 'hydropower nationalism' discourse presented hydropower development as a means to protect China's public and national interests. Under this discourse, the transnational environment NGO movement questioning hydropower development and advocating for indigenous people's rights were portrayed as a Western scheme to sow seeds of dissent within China. Rumors such as "Premier Wen Jiabao was coerced by NGOs into impeding hydropower development" (Xiaolan 2007) or that SEPA officials were against hydropower because they wanted to increase their own decision-making power were commonly used in this discourse.

Regarding cultivating pro-hydropower academics, in 2004, the Yunnan Power Company set up a "Yunnan Power Prize" worth 800,000 RMB to support research by the Yunnan Academy of Social Science. He Yaohua, former President of the Yunnan Academy of Social Science and Chairman of the Southwest National Research Association, wrote, collected and published papers in a book that supported hydropower development entitled "Nu, Lancang and Jinsha Rivers: Research on the exploitation of hydropower resources and the protection of the environment" (Jiangkun/Yaohua 2004). The publication was disseminated as policy input for decision-making by the Yunnan Province government and its senior leaders. In promoting hydropower development, this academic strategy reduced space for public debate on hydropower by framing hydropower decision-making as purely an academic and technical issue. Qin Guangrong, Vice Secretary of the Yunnan Provincial Party Committee and Executive Vice Governor, praised the role of the academy in supporting Yunnan's development (Guangrong 2004).

\subsubsection{Current Status of WEPT in Yunnan Province}

Although large hydropower development has been questioned by the public since the early 2000s, hydropower in Southwestern China continues to be built under the direction of various government agencies responsible for energy and the local government. By the end of 2014, the total installed capacity of hydropower in China had reached over 300 million kilowatts, accounting for a quarter of the world's total installed capacity (Hui 2015). However, as China's economy enters a new norm of less rapid economic growth and a restructuring of the economy away from energy intensive industries, hydropower developers have been left with an excess of power generation capacity (Lin et al. 2016). In response, as discussed in the energy reform pathway below, the government has proposed to expand electricity exports into Southeast Asia, and domestically to shift from WEPT to increasing demand in Yunnan Province itself. 


\subsubsection{Small Hydropower on Nu River Tributaries}

Following the official suspension of large hydropower dam plans in 2004, the $\mathrm{Nu}$ Prefecture government reoriented towards promoting small- and medium-scale hydropower. These plans, however, have also been backed by various Central Government policies since 1983, when the Ministry of Water Resources endorsed small hydropower projects for rural electrification. Investors from eastern areas of China, such as Shanghai and Zhejiang provinces, rushed into Southwestern China attracted by small hydropower's low initial investment and running costs.

There was, however, a lack of binding regulations, especially regarding small hydropower's environmental impacts. SEPA, which in 2008 was upgraded to the Ministry of Environment Protection, issued a "Notice on the Orderly Development of Small Hydropower to Effectively Protect the Ecological Environment" in June 2006. The $\mathrm{Nu}$ Prefecture government has also issued measures on small hydropower development and utilization management in 2007 and 2015 respectively. However, given the fact that the $\mathrm{Nu}$ Prefecture government was also promoting small hydropower, it tended to be flexible with regulations to encourage and enable development. In contrast to large hydropower projects, small hydropower projects are rarely reported on in the media, so there is a lack of public awareness. In the absence of policy constraints and public awareness, small hydropower has expanded rapidly in just a few years, with numerous legal violations and some dams even being built within the World Heritage site.

While accurate data is difficult to ascertain, according to some media reports, there were 45 companies developing small hydropower as of 2008, with agreements to build 85 power stations on 65 branches. WLE-Mekong (2018) document 21 hydropower dams of $15 \mathrm{MW}$ and above, and 10 irrigation dams with reservoir surface areas larger than 0.5 square kilometers. In a case study of 12 villages along the Dimaluo tributary river in Nu Jiang Prefecture, Ptak (2014) highlights that there are benefits and challenges. For instance, small-scale hydropower projects have brought some limited material benefits to relatively inaccessible rural ethnic minority communities; mainly this is linked to electricity production, but also is evidenced during the construction phase. Yet, the process of creating the projects have lacked participation and did not addressed multidimensional needs, such as access to employment opportunities nor improved access to education and health services. In his case study, Ptak found that the projects had also created difficulties for those who had been resettled (Ptak 2014).

Small hydropower is often presented as a means to help local communities increase their household income (as low electricity prices from small hydropower can help farmers reduce their household burden) and to protect forests by decreasing reliance on firewood for cooking and heating. However, uncoordinated small hydropower dam construction has also resulted in significant environmental degradation. The dams, canals, and diversion tunnels built by small hydropower stations can alter river channels and even cause the original river to sometimes dry up, leading to the disappearance of aquatic species that rely on specific niches or 
that cannot migrate. According to Kibler/Tullos (2013), small hydropower in the $\mathrm{Nu}$ River basin has resulted in a huge cumulative impact on the ecological environment, particularly with regard to habitat and hydrologic change. Furthermore, a significant proportion of the small hydropower dams are linked to mining projects nearby within the Nu River basin. In 2007, the local government had encouraged mining projects near to the hydropower stations to use their power, as there was insufficient transmission grid infrastructure to export the electricity farther away.

As investors built these power stations one by one, power generation grew incrementally, and generation overcapacity became an increasingly serious problem. In general, there is sufficient water for more power generation, but due to the lack of transmission grid infrastructure, most of the small power stations cannot run at full capacity. By the end of 2015, the Yunnan provincial government had halted further small hydropower construction on the $\mathrm{Nu}$ River.

\subsection{Civil Society River Protection Pathway}

Chinese environmental NGOs have played an important role in protecting the $\mathrm{Nu}$ River from large dam development, and are one of the major forces pushing for greater access to information and public participation. Key organizations have included: Green Watershed (GW), Green Earth Volunteers, and Friends of Nature. Pursuing existing legal means to mobilize public attention and support, these NGOs formed alliances through different networks to influence hydropower decision-making. They also drew on scientific assessments from renowned experts and field investigations to present the potential social, environmental and geological problems posed by the $\mathrm{Nu}$ River hydropower development plans to top-level officials to urge them to make informed decisions.

\subsubsection{Civil Society Strategies and Activities}

In early 2002, GW conducted a social impact assessment (SIA) in the area around the Manwan dam on the Lancang River, documenting the poverty that resettled migrants were living in. In June 2002, following the state-run Xinhua News' coverage of the Manwan dam's adverse impacts, Premier Zhu Rongji ordered the Yunnan Provincial government to verify the situation, resolve the dam-induced social issues, and compensate the Manwan dam-affected community for their losses. This research laid a strong foundation for GW's credibility to participate in the $\mathrm{Nu}$ River decision-making processes.

From November to December 2003, GW visited Beijing to establish a collaboration with other NGOs there, including Friends of Nature, Green Earth Volunteers, the Global Village, Conservation International, Wild China, Green Island and Home Watch Volunteers. In 2004, these environmental groups formed a 
loose coalition called the China River Network, later renamed the River Watching Network. The China River Network worked with member organizations to share resources, take collective action, and put pressure on groups promoting hydropower. They signed several petition letters to protect the Nu River, increasing social pressure on the government and the hydropower developers by mobilizing the general public in large numbers.

One of the most successful methods adopted by NGOs was building alliances with public figures, environmental officials, the China Democratic Party, and various experts and scholars in order to influence decision-making. While environmental officials, technical experts and scholars joined forces to promote protecting the Nu River, Wang Yongchen, a reporter for China National Radio and founder of Green Earth Volunteers, also liaised with a number of well-known writers, literary figures, and movie stars to influence the public. In October 2003, at the second Congress of the China Environmental Culture Promotion Association, Wang Yongchen mobilized 62 celebrated individuals from the fields of science and culture, along with media and civil society groups, to sign their names in opposition to the $\mathrm{Nu}$ River hydropower dams.

The China Democratic Party Yunnan Branch (DP) also disagreed with the positioning of hydropower as a main pillar of Yunnan's economy, especially with regards to the development of the $\mathrm{Nu}$ River. GW and the DP co-wrote a proposal submitted to the party's political consultation session in early February 2004. While the DP had always supported government decisions in the past, this time they were against $\mathrm{Nu}$ River hydropower development. These advocacy campaigns played a significant role in influencing Premier Wen Jiabao to suspend plans for $\mathrm{Nu}$ River hydropower development in 2004.

The NGO network's ability to garner support for a free-flowing Nu River cannot be viewed in isolation from the network's relationship with the media. From 2003 to 2006, there were hundreds of news reports on the environmental and social impacts of hydropower. Media in Yunnan had been warned that the phrase "Green Watershed" should not appear in local media. Despite this warning, media representatives poured in from other provinces to interview $\mathrm{GW}$ about the $\mathrm{Nu}$ River. In 2004, the "Nu River" was listed as the ninth most widely covered issue in China. Thus, the media amplified the voice of civil society. The People's Daily, Youth Daily, Economic Observer, 21st Century Economic Report, International Herald Tribune, South Reviews, Southern Weekend, and Beijing News all reported on the $\mathrm{Nu}$ River campaign at great length. Some reports were released at critical times to influence decision-making within the central government. It placed decision-making processes around hydropower development on the $\mathrm{Nu}$ River in the public spotlight.

Central to the perspective of civil society was that local communities should be positioned as policy actors rather than mere recipients of development policy. Linking policy-making at the national level with the need for representation of affected communities, GW arranged for 14 villagers from two potential resettlement communities in the $\mathrm{Nu}$ River basin to visit the Manwan Dam in May 2004 (Hongwei 2004). After seeing how local communities affected by the Manwan Dam made their living by collecting garbage, the trip participants shared their 
experiences with other villagers living along the $\mathrm{Nu}$ River. A documentary film maker, Shi Lihong, produced a video documenting the visit entitled "The Voice of the Nu River," which was shared widely. While arranging the visit held serious negative repercussions for $\mathrm{GW}$ and its ongoing work, the activity did push the government to solve the resettlement problems at the Manwan Dam and ensured that a new resettlement compensation policy was developed in Yunnan province. As a result, resettlement compensation rates were raised in 2005 from 5,000 RMB (in the case of the Manwan Dam) to 80,000 RMB per affected person, which includes the cost of rebuilding houses as well as community infrastructure such as new roads, schools and markets.

In October of 2004, a resettled community from the Tiger Leaping Gorge dam made history when five community representatives participated in a UN Conference on Dams and Sustainable Development co-organized by the UNDP, World Bank and the State Council in Beijing. At the conference, resettled people took advantage of the rare opportunity to engage in open dialogue with officials, including the Director General of the National Energy Agency (NEA), the Director of the Yunnan Resettlement Department, and the CEOs of dam companies. Based on this dialogue, the focus of the conference shifted from showing the magnificent achievements of hydropower development to exploring alternative means to reduce social and environmental impacts (Liangzhong/Ying 2005).

\subsubsection{The World Heritage Committee and Nu River Protection}

Following the listing of the Three Parallel Rivers as a World Natural Heritage site, Chinese NGOs and NGO representatives from 60 countries signed a letter during a conference held by the International Rivers Network in Thailand in November of 2003 requesting the World Heritage Committee (WHC) to give serious consideration to the potential harms of Nu River hydropower development. In July 2004, at the 28th World Heritage Conference, Chinese NGOs signed a joint letter to the WHC regarding dam development on the $\mathrm{Nu}$ River, and in April 2006, experts from the IUCN and UNESCO conducted an investigative trip to Yunnan (Kejia 2006). Their report pointed out that the main threats to World Natural Heritage sites on the Three Parallel Rivers include: hydropower development, mining, and development of the tourist industry (UNESCO 2006). It also identified that proposed adjustments would cause a $20 \%$ reduction in the original heritage site area. In general, if a heritage site is reduced by $20 \%$ it will likely be removed from the World Heritage list.

Based on the report, the 30th session of the WHC General Assembly held in July 2006 stated that the impact of exploratory activities for $\mathrm{Nu}$ River hydropower development is obvious, and that if the dam construction starts, it would have a very large impact to the $\mathrm{Nu}$ River's aesthetic value, and the naturally flowing river will be transformed into a series of reservoirs (Wang 2007). The WHC General 
Assembly asked the Chinese government to submit a status report on heritage protection to the WHC by February 2007.

In January 2007, the Chinese government submitted the status report, explaining that hydropower plans for the middle and lower reaches of the $\mathrm{Nu}$ River are currently the subject of ongoing research and debate. Their report noted, "there are strict laws and regulations in China to protect heritage sites. These regulations prohibit dam construction and mining activities within heritage sites." In June 2007, the Chinese government was required by the WHC to conduct a comprehensive scientific assessment of the impacts of dams and other projects on the environment of the "Three Parallel Rivers" in the middle reaches of the Nu River. According to the WHC, if the "Three Parallel Rivers" cannot be governed properly by 2008, the area will lose its World Heritage status.

The WHC specifically required that each project near the 'Three Parallel Rivers' disclose information to the public in a timely and transparent manner. Similarly, while the local government benefits from the site's World Heritage status, they must also be aware of their responsibility to protect the site, and must not over-develop tourism to increase income. The Ministry of Housing and Urban-Rural Development issued a warning to the local government that if they fail to protect the site, this will badly impact China's overall image. In the four years that followed, the 'Three Parallel Rivers' were monitored by the WHC.

In early 2016, GW, Green Earth Volunteers and Friends of Nature visited the NEA as concerned civil society organizations to call upon the administration to support the establishment of a national park, protect the World Heritage site, and prioritize ecological protection in the context of hydropower development. After this dialogue, seven NGOs (Friends of Nature, Green Earth Volunteers, GW, Green Han River, Hengduan Mountain Institute, Green Zhejiang and Chengdu Urban Rivers Association) collectively released an open letter appealing to the NEA to emphasize EIAs and public participation in the 13th five-year energy plan, particularly disclosure of hydropower plans on the $\mathrm{Nu}$ River. The dialogue and open letter were effective, as in the latter part of 2016, hydropower construction on the $\mathrm{Nu}$ River was excluded from the 13th Five-year Energy Development Plan, the 13th Five-year Renewable Energy Development Plan and the 13th Five-year Hydropower Development Plan.

\subsection{The Energy Reform Pathway}

As discussed above, the hydropower development pathway in Yunnan Province, including on the Nu River, was fundamentally shaped by the WEPT strategy. At the same time, China's electricity industry was undergoing profound reform. As noted above, in 2002, the state monopoly of the State Power Corporation was restructured into two state monopoly grid companies, and five state-owned power generation companies (the "Big Five") that were intended to compete alongside private and other state-owned investors in power generation. Wang/Chen (2012) highlight the 
slow pace of market-orientated reform after the initial creation of the "Big Five," suggesting that in contrast to the earlier monopoly in China, a "relative monopoly" now exists (see also Ngan 2010). Thus, these large state-owned enterprises have enjoyed the benefits of both market and planned economies (Dore et al. 2007). Meanwhile, China's 1996 Electricity Law encouraged the government to support renewable and clean energy for power generation, which incentivized the construction of large-scale hydropower dams for nation-wide electrification, as well as the construction of small hydropower stations to promote rural electrification. As noted before, the increasingly competition between the "Big Five" power companies accelerated the exploitation of Yunnan's hydropower resources (Han 2013).

Over the past couple of years, electricity markets in China's eastern industrial areas are now facing a power surplus (Solomon 2016). This is due to the global economic slowdown, as well as over-investment in coal and nuclear power generation, and China's trend towards less energy intensive industries. The installed capacity of Yunnan Province's hydropower is at present not fully utilized (Xiao n.d.), and the government's slogan has shifted since 2016 from 'WEPT' to "Yunnan Hydropower for Yunnan Use." Meanwhile, the Yunnan Provincial government, hydropower companies and power grid companies are also exploring opportunities to export power to neighboring countries such as like Laos, Vietnam, Bangladesh, Thailand and Myanmar (Yaqin 2016). For example, in 2015, China was already exporting approximately $70 \mathrm{MW}$ of electricity to Laos, with an agreement to export up to 3000 MW (RPTCC 2015).

Overall, a profound transformation of China's electricity sector is increasingly underway, incentivized by the need to reverse environmental degradation, meet international climate change obligations, clean up corruption, and address China's power surplus (Hao 2016). Technical solutions to meeting the country's energy demands are currently being proposed. The 13th Five-year Plan (2016-2020) responded to demands to reduce dependence on coal, develop clean and renewable energy, and enhance energy efficiency. China is also committed to achieving $15 \%$ non-fossil energy production by 2020 . Hydropower, however, in this context is considered essential to attaining this non-fossil energy target.

Yet, China's energy surplus has cooled down the fever to develop the Nu River dams, at least for the time being. Yunnan's high level of hydropower development can either be seen as over-exploitation of the provinces' natural resources, or as one of many steps towards a less carbon-intensive energy future (Magee/Henning 2017). Civil society groups argue that due to their social and ecological impacts large dams cannot be considered as clean energy. They argue that governance reform is required, namely: Firstly, (re)balancing the interests of various stakeholders, including restraining special interest groups and protecting public interests, especially the interests of disadvantaged groups. Secondly, clean relationships between government and enterprises must be fostered within the hydropower sector. Thirdly, the full and true costs of hydropower must be assessed, including impacts on watershed ecosystems and the rights of resettled communities and 
indigenous people. Lastly, hydropower governance must be improved, with increased transparency, public participation and accountability in decision-making (Xiaogang 2016).

\subsection{The National Park Pathway}

Now, over ten years since the suspension of hydropower construction, the Yunnan Provincial government and Nu Prefecture government is proposing the establishment of a national park. This pathway is still in the decision-making stage, and it is not yet clear how proposals for the $\mathrm{Nu}$ River Grand Canyon National Park will unfold given that the full plans are yet to be disclosed to the public.

In November 2012, the CPC Central Committee made the creation of an "Ecological Civilization" in China a national strategy, and subsequently issued a "Decision on Several Major Issues Concerning Comprehensive Deep Reform" in November 2013. The Central Committee State Council also issued "Opinions on Accelerating the Development of Ecological Civilization" and a "General Plan for the Reform of the Ecological Civilization System" in 2015, which supported the establishment of a national park system and the implementation of stricter protection measures within national parks. Such protection measures include prohibiting any construction and development that damages the ecosystem and affects indigenous people's homelands. Furthermore, these policies convey the importance of protecting the natural ecology and the authenticity and integrity of natural and cultural heritage.

This "national park pathway" was affirmed in the 13th Five-Year Plan (20162020). Although the outline of the plan proposed to coordinate hydropower development and ecological protection, the plan places high priority on ecological protection, and dictates scientific considerations for hydropower development in Southwestern China. The plan also mentioned establishing a national park system. However, despite this new direction in the national 13th Five-Year Plan, Yunnan's 13th Five-Year Plan Outline still makes mention in a couple of sentences to plans for the Nu River hydropower dams and suggests doing more follow-up work on it.

The Policy Research Office of the Yunnan Provincial government put forward the idea of a Nu River Grand Canyon National Park in 2007 (Yihua/Yaqi 2007). However, this pathway had not been fully considered within the context of the regional hydropower boom. Even as plans for large hydropower dams were shelved in 2004, the Nu Prefecture government still implemented an "electricity combined with mining" economic strategy, and spared no effort to promote small hydropower projects to this end. This situation continued until 2013, when the Yunnan Provincial Party Committee appointed a new Nu Prefecture Secretary. The new Secretary, Zhiyun Tong, led a delegation to visit national parks in the United States, and subsequently began the development of national parks in Yunnan Province in 2014. The Secretary of the Yunnan Provincial Party Committee declared on 25th January 2016 that all small hydropower and mining development on the $\mathrm{Nu}$ River 
would be stopped to protect the river's ecology and to support the Nu River Grand Canyon National Park proposal.

In May 2016, the Yunnan Provincial government approved the establishment of the $\mathrm{Nu}$ River Grand Canyon National Park. Later, the Secretary of Nu Prefecture stressed that national park construction was a new concept, and a step forward in promoting $\mathrm{Nu}$ River tourism development and ecological construction. He deemed this as the most suitable approach for Nu River development, incorporating both protection and utilization, in line with Premier Xi Jinping's statement: “clean waters and green mountains can bring us prosperity and wealth" (Jufen 2016).

The $\mathrm{Nu}$ River Grand Canyon National Park plan was approved by experts in August 2016, but as of the time of writing (January 2019) has not yet been publicly disclosed. Furthermore, the public, including indigenous people in local communities and NGOs, did not have the opportunity to give direct input on the $\mathrm{Nu}$ River Grand Canyon National Park plan. This despite the fact that in 2015, the Yunnan Provincial government had issued a National Park Management Regulation that encourages local community participation in national park management.

A number of problems have emerged in the pilot phase of establishing national parks in Yunnan Province, the first being ecological protection. For example, in Pudacuo National Park, which was established in 2007 in Shangri-La County, in order to increase income, the core area of the nature reserve was developed for tourism. Furthermore, the government's National Park Service became a liaison between tour companies, communities and government agencies. The fact that the National Park Service is supervising tourism development complicates the incentives for the National Park Service, as its funds are provided by tour companies. Meanwhile, in terms of community participation, local residents can only access low level employment opportunities, mainly cleaning work. Compensation for community members who lost their livelihoods with the establishment of the park consists mainly of cash compensation rather than sustainable livelihood capacity-building and reconstruction of their livelihoods.

The experience to date raises the question will the $\mathrm{Nu}$ River Grand Canyon National Park follow the old development model of government and capital domination and the neglect of minority community rights to participate in decision-making and to share benefits? Could it be possible that the development and management of the $\mathrm{Nu}$ River Grand Canyon National Park will ensure minority communities enjoying full access to information, inclusive participation and benefit sharing?

Regarding ecological conservation, the planned $\mathrm{Nu}$ River Grand Canyon National Park area does not cover the Nu River itself, the riverbanks and some small hydropower areas. This is because the National Park's boundaries, like those of the Three Parallel Rivers Protected Areas and existing Nature Reserves, cut off at a certain elevation. The Secretary of Nu Prefecture has stated that "National park construction does not affect the $\mathrm{Nu}$ River hydropower development or other industry development, so do not put them against each other" (Meng 2016). The argument posed by the Yunnan Province Forestry Department is that if the national park's boundaries include the Nu River itself, large number of people on both sides of the river would have to be resettled. The Yunnan Provincial Forestry Department 
said, "There is no direct relationship between the Nu River Grand Canyon National Park and halting Nu River hydropower development. If the national park covers the Grand Canyon, this means that the people on both sides of the river will be resettled, leading to a resettlement cost that is too high" (Meng 2016).

\subsection{Water Conservancy Pathway}

The final pathway we address is the Nu River water conservancy pathway, although very few details are available in the public domain. Interviews undertaken with government agencies for this research revealed that the $\mathrm{Nu}$ River is considered a very important freshwater resource, possibly even of higher value than its power generation capacity. This perspective has recently been incorporated into government planning documents.

In Yunnan Province's 13th Five-Year Plan Outline, there are three large- to medium- scale hydropower comprehensive utilization projects planned on the $\mathrm{Nu}$ River, namely Fugong, Lushui and Saige, with Lushui also being detailed as a key water conservancy infrastructure project. Furthermore, in the Nu Prefecture 13th Five-Year Water Conservancy Plan Recommendations, the Water Resources and Hydropower Planning and Design General Institute proposed that in order to achieve flood control, irrigation, water supply, power generation, and other benefits, the Nu River hydropower development plans should be adjusted for comprehensive utilization of water resources. Furthermore, more focus should be placed on the important role of comprehensive water resource utilization in poverty alleviation, ecological protection, and livelihood improvement. It proposes that to promote the comprehensive development and utilization of water resources on the $\mathrm{Nu}$ River, priority should be given to water conservation projects such as Maji, Yabiluo, Lushui and Saige, which it suggests have great potential benefits, with little environmental impact. The Lushui water conservancy project, it states, can not only provide irrigation water to more than $300,000 \mathrm{mu}$ of farmland downstream ( $1 \mathrm{mu}=$ $666 \mathrm{~m}^{2}$ ), but can also supply water to households, as well as contribute to industrial and drinking water supplies in rural areas for Lushui County and some townships in the Baoshan Prefecture area. In a meeting between the Nu Prefecture government and the Ministry of Water Resources (MWR) in December 2016, the Secretary of the $\mathrm{Nu}$ Prefecture government proposed that comprehensive development of the $\mathrm{Nu}$ River water resource poses a fundamental solution to ecological protection and is the key to poverty alleviation in $\mathrm{Nu}$ Prefecture.

In summary, it seems that the rationality of the hydropower development pathway of the $\mathrm{Nu}$ River is moving towards that of water conservancy projects. Dams will likely shift their function from solely power generation to more comprehensive functions, including water supply, irrigation, flood control and drought resistance. So far, the local government and MWR are the main proponents of this pathway. There were initial indications that the $\mathrm{Nu}$ River Basin Comprehensive Plan may be approved in the first half of 2017, but as of the time of writing (January 
2019) there has been no further details disclosed publicly. GW had applied to the Yangtze River Water Resources Commission for information disclosure in 2016, but received a response that the information involved state secrets so they were unable to provide access.

\subsection{Conclusion}

The analysis of pathways discussed above reveals that there are many possible alternatives for the $\mathrm{Nu}$ River. However, not every pathway has been given equal consideration.

There is no doubt that in the context of the national strategy of Western Development and WEPT, the hydropower development pathway has been given more consideration. Hydropower proponents have more power, money, resources, technology and knowledge, and include the NDRC and the NEA in positions of authority, local government, hydropower companies, and academics who use professional knowledge to promote hydropower development. Also important is that decision-making processes about the $\mathrm{Nu}$ River hydropower projects to date have proceeded without complete information disclosure and public participation, and have not fully taken account of the objections to the plans.

The civil society river protection pathway led by China's environmental NGOs was originally in a marginalized position, but the NGOs' ongoing actions introduced civil society voices to China's central leadership. The history of the Nu River protection since 2003 shows that civil society can participate in and promote more inclusive, informed and responsible decision-making processes. As a result of the tireless efforts of China's environmental NGOs, the Nu River avoided the fate of other dammed rivers, and its natural heritage and ecosystems remain largely intact.

Over more than 10 years of disagreement between the proponents of big hydropower development versus those seeking natural heritage protection, the local government consistently waited for decisions to be handed down by the central government, instead of pursuing other development pathways. Economic development and living standards in the Nu River basin are behind those of other regions in Yunnan, but the ecological environment has been maintained. When central authorities proposed the creation of an Ecological Civilization in China, the $\mathrm{Nu}$ Prefecture government only then made a choice to work on poverty alleviation and approved the national park's creation as a development pathway.

In recent years, China's leaders have promoted new development concepts, including innovation, coordination, and green, open and shared development. The national park pathway for the $\mathrm{Nu}$ River has the potential to provide more opportunities for local people and nature to coexist sustainably. However, the future of the $\mathrm{Nu}$ River remains uncertain, as the local government and the energy administration of the central government have not completely abandoned the $\mathrm{Nu}$ River hydropower plans, and there remains much resistance to public participation and information disclosure which are necessary for sustainable development. One of the 
biggest indicators of this resistance to public participation is the fact that the $\mathrm{Nu}$ River basin comprehensive plan has been kept confidential. Therefore, most importantly, decision-making about which development pathway is chosen for the future for the $\mathrm{Nu}$ River, should be inclusive, informed and accountable to ensure that the rights and entitlements of ethnic communities living along the river are recognized.

\section{References}

Bizhong, C. (2004, July 17). In addition to hydropower, is there any other choice for the Nu people out of poverty? 21st Century Economic Report. Retrieved from: http://www.china.com.cn/ chinese/difang/612599.htm.

Chaofei, Y. (2003). Examining the ecological mire of dam construction: a new decision-making framework. Water Resources and Electric Power. 4, 38-42.

Dore, J., Yu, X., \& Li, K. (2007). China's energy reforms and hydropower expansion in Yunnan. In L. Lebel, J. Dore, R. Danial \& Y.S. Koma (Eds.), Democratizing water governance in the Mekong region (pp. 55-92). Chiang Mai, Thailand: Mekong Press.

Guangrong, Q. (2004). Opening ceremony of the seminar on hydropower resources exploitation and environmental protection of Nu River, Lancang River and Jinsha River. In F. Jiangkun \& H. Yaohua (Eds.), Nu River, Lancang River and Jinsha River: Researches on the exploitation of hydropower resources and the protection of environment. China: Social Sciences Academic Press.

Han, H. (2013). China's policymaking in transition: a hydropower development case. Journal of Environment \& Development, 22(3), 313-336.

Hao, F. (2016, April 7). China puts an emergency stop on coal power construction. The Diplomat. Retrieved from: http://thediplomat.com/2016/04/china-puts-an-emergency-stop-on-coalpower-construction/.

Hao, W. (2000, November 20). Accelerating the development of pillar industry in Yunnan. Xinhua Net. Retrieved from: http://www.people.com.cn/GB/channel3/26/20001120/319639.html.

Hongwei, Y. (2004, June 2). Dam or not? Indigenous people from the Nu River visited Manwan. South Reviews. Retrieved from: http://finance.sina.com.cn/roll/20040602/1121791662.shtml.

Hui, L. (2015, May 19). Hydropower installed capacity of China accounted for one quarter of the world. Xinhua Net. Retrieved from: http://news.xinhuanet.com/finance/2015-05/19/c_ 1115339094.htm.

Jiangkun, F., \& Yaohua, H. (Eds). (2004) Nu, Lancang and Jinsha Rivers: Research on the exploitation of hydropower resources and the protection of the environment. China: Social Sciences Academic Press.

Jufen, Y. (2016, June 7). The Nu prefecture government held national park construction meeting. Retrieved from the Forestry Department of Yunnan Province website: http://www.ynly.gov.cn/ yunnanwz/pub/cms/2/8407/8415/8477/107222.html.

Kejia, Z. (2006, June 18). World Heritage 'three parallel rivers' is facing threats. China Youth Daily. Retrieved from: http://zqb.cyol.com/content/2006-07/18/content_1449846.htm.

Kibler, K.M., \& Tullos, D.D. (2013). Cumulative biophysical impact of small and large hydropower development in Nu River, China. Water Resources Research, 49(6), 3104-3118.

Leach, M., Scoones. I., \& Stirling, A. (2010). Dynamic sustainabilities: Technology, environment, social justice. Abingdon, United Kingdom: Earthscan.

Liangzhong, X., \& Ying, X. (2005). The rational appeal of Jinsha River farmers. China Society Periodical, 15, 16-19. 
Lin, J., Liu, X., \& Kahrl, F. (2016) Excess capacity in China's power systems: A regional analysis. Commissioned by the Energy Foundation through the U.S. Department of Energy. Berkeley, CA: Ernest Orlando Lawrence Berkeley National Laboratory.

Magee, D. (2006). Powershed politics: Yunnan hydropower under Great Western Development. China Quarterly, 185, 23-41.

Magee, D., \& Henning, T. (2017, April 27). Hydropower boom in China and along Asia's rivers outpaces electricity demand. China Dialogue. Retrieved from: https://www.chinadialogue.net/ article/show/single/en/9760-Hydropower-boom-in-China-and-along-Asia-s-rivers-outpaces-ele ctricity-demand.

Meng, Z. (2016, September 19). The Nu River Grand Canyon National Park will not include the grand canyon. The Paper News. Retrieved from: http://www.thepaper.cn/newsDetail_forward_ 1530425.

Ngan, H.W. (2010). Electricity regulation and electricity market reforms in China. Energy Policy, 38(5), 2142-2148.

$\mathrm{Nu}$ Prefecture Forestry Bureau. (2015). Brief introduction of the Nu prefecture forestry.

Ptak, T. (2014). Dams and development: Understanding hydropower in far Western Yunnan Province, China. Focus on Geography, 57(2), 43-53.

Ptak, T., \& Hommel, D. (2016). The trans-political nature of Southwest China's energy conduit, Yunnan Province. Geopolitics, 21(3), 556-578.

Peiyan, Z. (2010). WEPT: to create a new pattern of China's power development. CPC History Studies, 3, 5-13.

Ronghua, W. (2012, December 3). Interpretation of ecological civilization. Wenhui Daily. Retrieved from: http://theory.people.com.cn/n/2012/1203/c40531-19774896-1.html.

RPTCC. (2015). Summary of Proceedings: 19th Meeting of the GMS Regional Power Trade Coordination Committee (RPTCC-19). Bangkok, Thailand: Asian Development Bank.

Solomon, D. (2016, June 16). China's impressive clean energy progress confronted by emerging challenges. East by Southeast. Retrieved from: http://www.eastbysoutheast.com/chinasimpressive-clean-energy-progress-confronted-by-emerging-challenges/.

Tingzhen, L. (2010). Investment attraction but the local government was captured by central enterprises. Economy \& Nation Weekly, 25, 32-33.

UNESCO. (2006). Convention concerning the protection of the world cultural and natural heritage. Thirtieth session. Vilnius, Lithuania 8-16 July 2006. Retrieved from: https://whc. unesco.org/archive/2006/whc06-30com-7b.addE.pdf.

Wang, Q., \& Chen, X. (2012). China's electricity market-oriented reform: From an absolute to a relative monopoly. Energy Policy, 51, 143-148.

Wang, Y. (2007). A yellow card for the Three Parallel Rivers. China Dialogue. Retrieved from: https://www.chinadialogue.net/article/show/single/en/1200-A-yellow-card-for-the-Three-Parall el-Rivers.

WCD. (2000). Dams and development: A new framework for decision-making. The Report of the World Commission on Dams. London, United Kingdom: Earthscan.

WLE-Mekong. (2018). Greater Mekong Dams Observatory. Retrieved from: https://wle-mekong. cgiar.org/changes/our-research/greater-mekong-dams-observatory/.

Xiao, F. (n.d.). China's energy demands do not need such a large-scale hydropower development. Green Earth Volunteers. Retrieved from: http://www.chinagev.org/index.php/greenpro/ environmentview/5392-zhonggbuxuyaorucidaguimoshuidiankaifa.

Xiaobing, W. (2003, February 20). The whole story of power reform program. Finance \& Economy.

Xiaogang, Y. (2016). What is the future of hydropower governance? REEI energy system transformation workshop.

Xiaolan, Y. (2007, November 6). Zhang Boting: preacher of hydropower science popularization in China. Yunnan Electric Power News. Retrieved from: http://www.hydropower.org.cn/ showNewsDetail.asp?nsId=112.

Xiaohui, L., \& Baiying, X. (2010, August 2). Re-emergence of enclosure boom in hydropower market. China Securities News. 
Yaohua, H., \& Jiankun, F. (2004). The scientific outlook on development and the hydroelectric exploitation of Nu Jiang. In F. Jiangkun \& H. Yaohua (Eds.), Nu River, Lancang River and Jinsha River: Researches on the exploitation of hydropower resources and the protection of environment. China: Social Sciences Academic Press.

Yaqin, J. (2016, February 23). Hydropower overcapacity in Yunnan is expected to alleviate, the key is the national market and the international market. China Energy News.

Yihua, M., \& Yaqi, Z. (2007, February 25). Yunnan province will use 10 years to build a 'national park' system. Spring City Evening News. Retrieved from: http://news.sohu.com/20070225/ n248338027.shtml.

Yikun, H. (2004, April 11). The Nu River hydropower planning need to do re-EIA. The Economic Observer. Retrieved from: http://finance.sina.com.cn/b/20040411/1446712692.shtml.

Yonglin, T. (2006, March 20). 1996-2000: Macro-economic control and soft landing during 9th five-year period. China Youth Daily. Retrieved from: http://zqb.cyol.com/content/2006-03/20/ content_1338340.htm.

Yu, X., Chen, X., Middleton, C., \& Lo, N. (2018, March). Charting new pathways towards inclusive and sustainable development of the Nu River Valley. Kunming and Bangkok: Green Watershed and Center for Social Development Studies, Faculty of Political Science, Chulalongkorn University.

Open Access This chapter is licensed under the terms of the Creative Commons Attribution 4.0 International License (http://creativecommons.org/licenses/by/4.0/), which permits use, sharing, adaptation, distribution and reproduction in any medium or format, as long as you give appropriate credit to the original author(s) and the source, provide a link to the Creative Commons license and indicate if changes were made.

The images or other third party material in this chapter are included in the chapter's Creative Commons license, unless indicated otherwise in a credit line to the material. If material is not included in the chapter's Creative Commons license and your intended use is not permitted by statutory regulation or exceeds the permitted use, you will need to obtain permission directly from the copyright holder. 